\title{
Rotura de cuerpos cavernosos y de uretra durante la actividad sexual
}

\section{Breakage of cavernous bodies and urethra during the sexual intercourse}

\section{Sr. Director}

La fractura de pene es una entidad infrecuente, y la asociación de lesión uretral se da en un $10-38 \%^{1,2}$ de los casos. Esta urgencia urológica ocurre por traumatismo contra el pubis o periné de la pareja con el pene en erección durante el coito, por presentar este una menor movilidad y menor espesor de la túnica albugínea que en estado de flacidez ${ }^{3,5}$. Actualmente, el tratamiento quirúrgico es el más aceptado.

Se presenta el caso de un varón de 30 años que acudió al servicio de urgencias por dolor agudo en el pene y uretrorragia masiva durante una relación sexual. Como antecedente tóxico previo a la relación sexual presentaba consumo de cocaína. En la exploración física destacaba la presencia de un hematoma en cara ventral del pene en el tercio distal. Mediante un vendaje compresivo se logró el control de la hemorragia.

En la RNM se nos informa de la existencia de un hematoma de $2,5 \mathrm{~cm}$ entre los cuerpos cavernosos con efecto masa entre estos y la uretra (fig. 1), y de discretas heterogeneidades de la señal en los cuerpos cavernosos que podrían corresponderse con zonas de ruptura.

Se intervino quirúrgicamente realizando una incisión coronal circunferencial, con liberación de los cuerpos cavernosos y del borde posterior de uretral, suturando las lesiones con puntos sueltos de vicryl $4 / 0$. Se procedió a realizar un vendaje compresivo y a la colocación de una sonda de Foley $14 \mathrm{Ch}$. La cobertura antibiótica se realizó con ceftriaxona $1 \mathrm{~g}$ en $24 \mathrm{~h}$, y se administraron AINE.

La evolución fue favorable, ya que tres meses después el paciente presentó una función eréctil normal, y la flujometría normal descartó la existencia de una estenosis de uretra residual.

El segundo caso es el un varón de 29 años que durante una relación sexual presentó dolor agudo en el pene y uretrorragia. Como antecedente tóxico previo a la relación sexual refería consumo de marihuana. A la exploración física destacaba un hematoma penoescrotal, una uretrorragia y una solución de continuidad en el cuerpo cavernoso derecho.

Se realizó una RNM gracias a la cual se diagnosticó una rotura del cuerpo cavernoso derecho en el tercio proximal, con un hematoma de $4,5 \mathrm{~cm}$ (fig. 2) que rompía la túnica albugínea del cuerpo cavernoso abombando la cara ventral peneana y desplazando contralateralmente el cuerpo esponjoso.

Se intervino quirúrgicamente de urgencia siguiendo el mismo procedimiento que en el caso anterior. La evolución fue también buena, presentando erecciones rígidas, indoloras y sin incurvación peneana, y sin la presencia de estenosis uretral residual.
La presentación característica de la fractura de pene es la audición de un chasquido tras el traumatismo sobre el pene erecto, con una rápida pérdida de la erección ${ }^{6}$, con o sin dolor acompañante ${ }^{7}$, incurvación del pene hacia el lado contrario a la fractura y aparición de un hematoma genital exclusivamente peneano en la mayoría de los casos. Si existe lesión de la fascia de Buck, el hematoma puede extenderse hacia el área escrotal, perineal o hipogástrica, quedando limitada por la fascia de Colles. La presencia de uretrorragia, sangre en el meato uretral o retención urinaria son signos sugestivos de lesión uretral asociada.

El diagnóstico de la fractura de cuerpos cavernosos es clínico, mediante la historia clínica y la exploración física. Puede utilizarse también alguna prueba de imagen como la uretrocistografía retrógrada, la cavernosografía, la ecografía o la RNM. La uretrografía retrógrada está indicada en caso de síntomas o signos de lesión uretral, como uretrorragia o imposibilidad para el sondaje. La cavernosografía se realiza

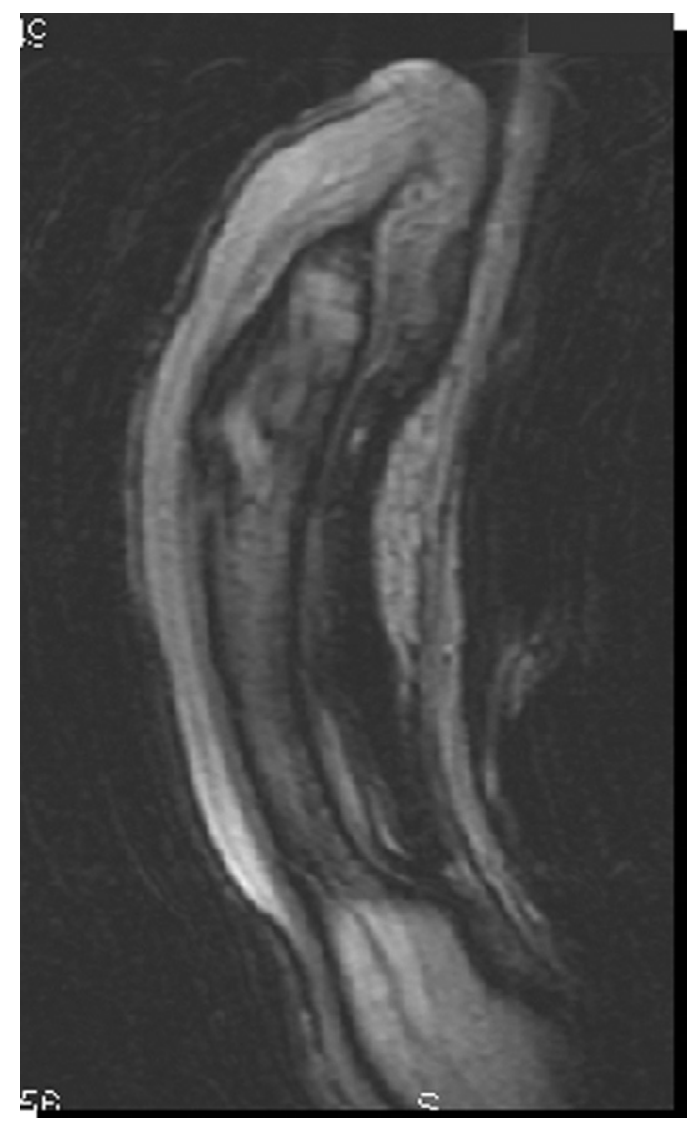

Figura 1 - Hematoma de $2,5 \mathrm{~cm}$ con efecto masa entre cuerpos cavernosos y uretra, y rotura del cuerpo cavernoso. 


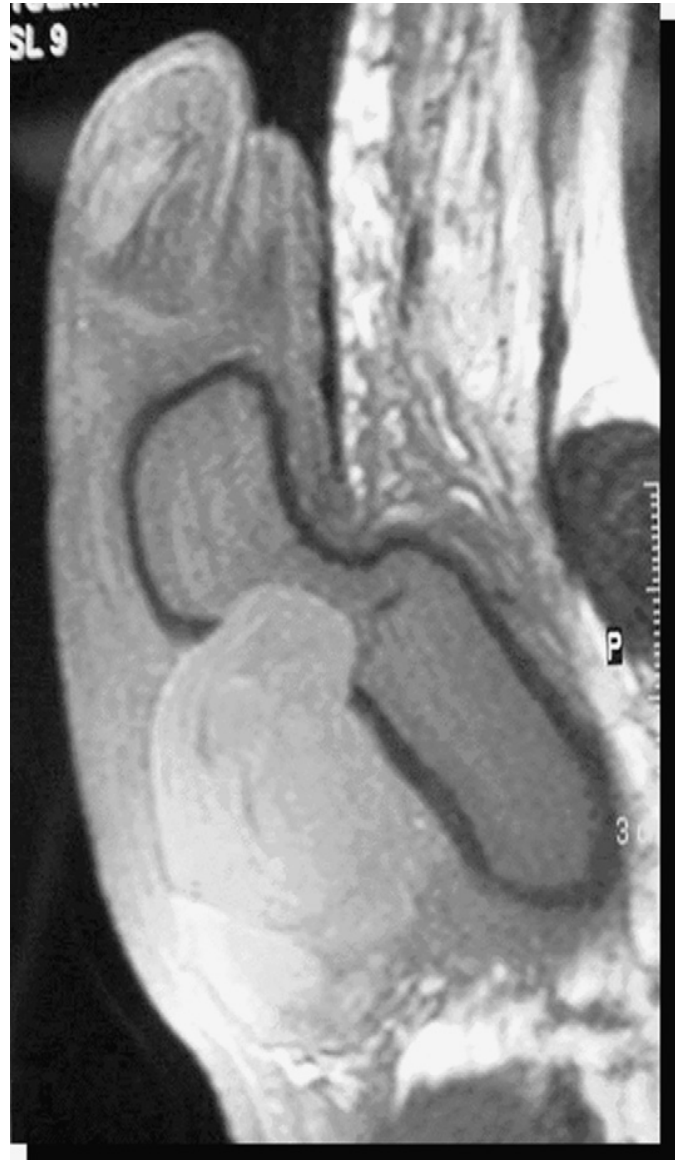

Figura 2 - Rotura del cuerpo cavernoso.

mediante la inyección de un contraste yodado en los cuerpos cavernosos, siendo diagnóstica la presencia de extravasación de contraste en la localización de la fractura. Su uso se está abandonando no solo por los falsos negativos que se producen en el caso de pequeñas fisuras o por rápido taponamiento de la herida albugínea por un coagulo, sino también por el riesgo de reacciones al contraste yodado, infección y aumento de la fibrosis por extravasación del medio de contraste ${ }^{3,4,9}$. La ecografía es una prueba no invasiva que permite visualizar el hematoma, y en ocasiones la fractura cavernosa, que se visualiza como un área hipoecoica que altera la continuidad de la túnica albugínea $^{3-5,8}$. En su contra, está la difícil detección de pequeñas roturas y la necesidad de ecografistas adiestrados que interpreten de forma adecuada la prueba. La RNM constituye actualmente el método diagnóstico más fiable ${ }^{9}$, porque ofrece una excelente visualización de la porción pendular del pene y en particular de la túnica albugínea.

El diagnóstico diferencial se establece principalmente con la rotura de la vena dorsal profunda del pene, que se produce por el mismo mecanismo traumático y se manifiesta clínicamente de forma similar ${ }^{3,5,8}$.

En lo que se refiere al tratamiento, hasta los años setenta el tratamiento de elección era el conservador, mediante sondaje uretral o cistostomía si este no era posible, vendaje compresivo, hielo local, antibióticos, analgésicos y sedantes para evitar la erección ${ }^{3,4}$. Como secuelas podían aparecer placas fibrosas en la zona de la rotura, incurvación del pene, erección dolorosa y estenosis de uretra ${ }^{4}$. Actualmente, el tratamiento conservador sólo se sigue cuando la indemnidad de la túnica albugínea es confirmada por las pruebas diagnósticas. En los demás casos, la exploración quirúrgica sin demora ${ }^{7}$ es obligada, para evitar que el hematoma se organice. Cuando el lugar de la fractura está bien localizado y el hematoma es de pequeño tamaño, se realiza una incisión longitudinal sobre el mismo ${ }^{3,4}$, pero cuando hay un gran hematoma o existe lesión uretral asociada, es más aconsejable una incisión coronal circunferencial ${ }^{10}$, que permite una fácil evacuación del hematoma, y la reparación de la fractura albugínea y la lesión uretral.

B I B L I O G R A F Í A

1. Rodríguez A, González A, Cespón E, Bonelli C, Lorenzo J, Cuerpo MA. Fractura de pene. Aportación de un caso. Actas Urol Esp. 2001;25:765-9.

2. Sant GR. Rupture of the corpus cavernosum of the penis. Arch Surg. 1981;116:1176-8.

3. Lema J, Blanco M, Cimadevila A, Rodríguez H, Tato J. Fractura de pene con afectación de cuerpos cavernosos y uretra. Actas Urol Esp. 1999;23:900-3.

4. Tejido A, Martin MP, Villacamp F, de la Morena JM, Suárez A. Tratamiento quirúrgico de la fractura de pene. Nuestra experiencia. Actas Urol Esp. 1999;23:784-8.

5. Lorenzo JG, Segura M, Salinas M, Pastor JM, Hernández I, Martínez M. Rotura de cuerpos cavernosos: evaluación y manejo terapéutico. Actas Urol Esp. 1999;23:635-9.

6. Dincel C, Caskurln T, Resim S, Bayraktar Z, Tasci Al, Sevin G. Fracture of the penis. Int Urol Nephrol. 1998;30:761-5.

7. Tan LB, Chiang CP, Huang CH, Chou YH, Wang CJ. Traumatic rupture of the corpus cavernosum. Br J Urol. 1991;68:626-8.

8. Mariño J, Senovilla JL, Mateos J, Abengozar A, Sevilla M, Caballero M. Fractura de pene. Revisión de la literature y presentación de dos casos. Actas Urol Esp. 2000;24: 767-70.

9. Fedel M, Venz S, Andreessen R. Sudhoff F, Loening SA. The value of magnetic resonante imaging in the diagnosis of suspected penile fracture with atypical clinical findings. J Urol. 1996;155:1924-7.

10. Mydlo JH, Hayyeri M, Macchia RJ. Urethrography and cavernosography imaging in a small series of penile fractures: a comparison with surgical findings. Urology. 1998;51:616-9.

\section{Las Heras Alonso*, R. Puig Giró, H. Las Heras Alonso y J. Guajardo Guajardo}

Servicio de Urología, Hospital Universitario Arnau de Vilanova, Lleida, España

*Autor para correspondencia.

Correo electrónico: martamireia@hotmail.com

(M. Las Heras Alonso). 